Halaman 92-99

\title{
Pengaruh Model Project Based Learning (PjBL) terhadap Kemampuan Berpikir Kritis Siswa Kelas X SMA Negeri 2 Karanganyar Tahun Pelajaran 2012/2013
}

\author{
The Effect of Project Based Learning (PjBL) on the Critical Thinking Ability \\ of the X Graders of SMA Negeri 2 Karanganyar in Academic Year Of 2012/2013 \\ Dwi Eka Yanti, Puguh Karyanto, Bowo Sugiharto \\ Pendidikan Biologi FKIP Universitas Sebelas Maret \\ Jl. Ir. Sutami 36 A Surakarta \\ Email: dwiekay@yahoo.co.id
}

Diterima 18 Juli 2013, disetujui 12 September 2013

\begin{abstract}
This research aimed to find out whether or not there is an effect of Project Based Learning (PjBL) on the critical thinking ability of the X graders of SMA Negeri 2 Karanganyar in biology subject in the school year of 2012/2013. This study was a quasiexperimental research using Post-test Non Equivalent Group Design using cluster sampling. The population of research was all $\mathrm{X}$ graders of SMA Negeri 2 Karanganyar in the school year of 2012/2013 consisting of 288 students, while the sample consisted of two classes: control one containing 33 students and experiment one containing 35 students. The control class employed varied lecturing learning method and the experiment one employed Project Based Learning (PjBL) model. Technique of collecting data used was test item and observation sheet. The research hypothesis testing was done using ttest.The result of research showed that Project Based Learning (PjBL) model affected the students' critical thinking ability. The mean score of critical thinking ability in the experiment class employing Project Based Learning (PjBL) model in learning was higher than that in control class employing varied lecturing method.The conclusion of research was that Project Based Learning (PjBL) model affected significantly the critical thinking ability of the second semester of the X graders of SMA Negeri 2 Karanganyar in the school year of 2012/2013.
\end{abstract}

Key Words: Project Based Learning (PjBL) , critical thinking ability

\section{Pendahuluan}

SMA N 2 Karanganyar merupakan salah satu SMA di Karanganyar yang sukses dalam ujian nasional. Hal tersebut dapat dilihat dari nilai rata-rata ujian nasional program IPA mata pelajaran biologi tahun 2010 hingga 2012 pada Tabel 1.1 :

Table 1.1 Nilai Rata-Rata Ujian Tahun 2010 hingga 2012

\begin{tabular}{llllll}
\hline & & \multirow{4}{l}{ Nilai rata-rata } \\
\cline { 3 - 5 } $\mathrm{N}$ & Pro- & Mapel & Tahun & Tahun & Tahun \\
$\mathrm{o}$ & gram & & 2010 & 2011 & 2012 \\
\hline 1. & IPA & Biologi & 6,45 & 7,89 & 8,52 \\
\hline
\end{tabular}

(Sumber: Balitbang kemendiknas, 2013)

\section{Berdasarkan Tabel 1.1, dapat} dilihat bahwa nilai rata-rata ujian nasional program IPA mata pelajaran biologi di atas standar nilai yang telah ditetapkan yaitu 5,5. Namun, berdasarkan analisis soal yang dilakukan berdasarkan pada kata kerja operasional merujuk pada taksonomi Bloom, soal yang diberikan hanya mencakup aspek kognitif C1 hingga C4. Hasil analisis dapat diikhtisarkan pada Tabel 1.2. 
Tabel 1.2 Analisis Butir Soal

\begin{tabular}{lllllll}
\hline $\begin{array}{l}\text { Tahun } \\
\text { (Kode) }\end{array}$ & \multicolumn{6}{c}{ Aspek Kognitif(\%) } \\
\cline { 2 - 7 } & C1 & C2 & C3 & C4 & C5 & C \\
& & & & & & 6 \\
\hline $2010(\mathrm{~A})$ & 62,5 & 7,5 & 15 & 12,5 & - & - \\
$2011(\mathrm{~A})$ & 32,5 & 22,5 & 27,5 & 15 & - & - \\
$2012(\mathrm{~A})$ & 22,5 & 20,0 & 37,5 & 17,5 & - & - \\
\hline
\end{tabular}

Tabel 1.2 menunjukkan bahwa soal biologi UN 2010-2012 yang diberikan meliputi aspek kognitif berupa mengingat, memahami, menganalisis, dan belum terdapat aspek kognitif untuk mengevaluasi serta menciptakan.

Ditinjau dari dimensi pengetahuan kognitif, soal yang diberikan hanya mencakup dimensi pengetahuan konseptual dan prosedural, belum mencakup dimensi pengetahuan faktual dan metakognisi. Soal UN yang hanya menekankan pada ranah kognitif $\mathrm{C} 1$ hingga $\mathrm{C} 4$, mengakibatkan pembelajaran hanya berpusat pada proses penyampaian dan penerimaan konsep.

Selain fenomena menyangkut dimensi pengetahuan dan aspek-aspek kognitif di atas, terdapat fenomena lain yaitu bahwa pembelajaran lebih menitikberatkan pada pemberian konsep secara tekstual. Proses pembelajaran tekstual dapat mengakibatkan siswa tidak dapat memberdayakan daya nalar dalam memecahkan permasalahan dan mengaplikasikan konsep-konsep yang telah dipelajari dalam kehidupan nyata (Yamin,2008; Daroni, 2002; Apriono,2009). Proses pembelajaran tekstual tersebut, akan mengakibatkan kemampuan berpikir kritis siswa rendah (Apriono,2009).

Kemampuan berpikir kritis merupakan kemampuan untuk memahami masalah dan pendapat, kemampuan menyeleksi informasi dan hipotesis yang penting serta relevan untuk menyelesaikan masalah serta kemampuan untuk menarik kesimpulan yang valid (Amri \& Ahmadi, 2010). Kemampuan berpikir kritis menurut Facione (2013) meliputi interpretation, analysis, evaluation, inference, explanation, dan self-regulation. Pengembangan kemampuan berpikir kritis merupakan integrasi beberapa bagian pengembangan kemampuan, seperti pengamatan (observasi), analisis, penalaran, penilaian, dan pengambilan keputusan. Semakin baik pengembangan bagian-bagian dari kemampuan tersebut kemampuan berpikir kritis juga lebih berkembang. Berpikir kritis dapat diajarkan melalui kegiatan laboratorium, penemuan, pekerjaan rumah yang dapat mengembangkan kemampuan berpikir kritis, dan ujian yang dirancang untuk membangun kemampuan berpikir kritis. Pertanyaan-pertanyaan tingkat tinggi (high level question) dapat mendorong pemikiran kritis yang lebih mandalam. Kemampuan berpikir kritis dapat ditingkatkan melalui diskusi kelompok 
yang tertata dan dibimbing langsung oleh guru. Berpikir kritis dapat dibangun dengan membangun iklim kelas yang didalamnya pemikiran dan analisis benarbenar dihargai keberadaanya (Jacobsen, Eggen, \& Kauchak, 2009).

Permasalahan pembelajaran yang lebih menitikberatkan pada pemberian konsep secara tekstual mengakibatkan kemampuan berpikir kritis siswa kurang berkembang. Berdasarkan permasalahan tersebut, pendekatan kontekstual yang berlandaskan paradigma konstruktivisme merupakan salah satu solusi agar siswa tidak hanya mengingat, menghafal dan memahami konsep. Menurut Martin et al. (2002) dengan landasan konstruktivisme, siswa akan mampu meningkatkan keterampilan berpikir kritis (Suryawati, 2012). Model, strategi, dan pendekatan yang mengembangkan kemampuan berpikir kritis siswa diantaranya: Experiential Learning (Lestari, 2012), pembelajaran inkuiri (Praptiwi, 2007), strategi pembelajaran Blended Learning (Cahyadi, 2011), Problem Based Learning (Adnyana, 2008) dan Project Based Learning (Luthvitasari, 2012).

Model Project Based Learning $(P j B L)$ adalah model pembelajaran yang berfokus pada ide-ide siswa, yaitu membentuk gambaran sendiri dari topik atau peristiwa yang relevan dan persoalan yang sesuai dengan pengalaman siswa sehari-hari (Susanti,2008). Model Project Based Learning $(P j B L)$ didesain agar siswa melakukan investigasi untuk memahami suatu persoalan (Mahanal,2009). Modal PjBL memiliki enam tahapan diantaranya, start with the essential question, design a plan for the project, Create a schedule, monitor the student and progress of the project, asses the outcome, dan evaluate the experience.

\section{Model Project Based Learning} (PjBL) memiliki beberapa kelebihan diantaranya meningkatkan motivasi, meningkatkan kemampuan pemecahan masalah, meningkatkan kolaborasi atau kerja kelompok, dan meningkatkan ketrampilan memanfaatkan benda-benda di sekitarnya (Susanti, 2008). Model Project Based Learning (PjBL) memiliki beberapa kelebihan dibandingkan model berbasis masalah yang lain di antaranya; 1) Model Project Based Learning (PjBL) menciptakan produk akhir sebagai hasil dari proses pemecahan masalah namun masih menitikberatkan pada ketrampilan prosesnya; 2) Manajemen proyeknya lebih terarah (Schneider, 2005) dan 3) Meningkatkan ketrampilan memanfaatkan benda-benda di sekitarnya (Susanti, 2008).

Berdasarkan paparan di atas, diketahui terdapat beberapa model, 
strategi atau pendekatan yang dapat memberdayakan kemampuan berpikir kritis. Namun, model Project Based Learning (PjBL) memiliki kelebihan diantara model, strategi atau pendekatan berbasis masalah yang telah disebutkan sebelumnya. Berdasarkan hal tersebut, untuk membuktikan apakah Project Based Learning (PjBL) dapat memberdayakan atau dapat mempengaruhi kemampuan berpikir kritis siswa, perlu diadakan penelitian dengan judul Pengaruh Model Project Based Learning (PjBL) Terhadap Kemampuan Berpikir Kritis Siswa Kelas X Sma Negeri 2 Karanganyar Tahun Pelajaran 2012/2013.

\section{Rumusan Masalah}

Rumusan masalah dalam penelitian adalah apakah terdapat pengaruh model Project Based Learning $(P j B L)$ terhadap kemampuan berpikir kritis siswa X SMA N 2 Karanganyar.

\section{Tujuan Penelitian}

Tujuan penelitian yang dilakukan adalah untuk mengetahui adanya pengaruh model Project Based Learning $(P j B L)$ terhadap kemampuan berpikir $\begin{array}{llllll}\text { kritis siswa kelas } & \mathrm{X} & \text { SMA } & \mathrm{N} & 2\end{array}$ Karanganyar.

\section{Manfaat Penelitian}

1. Manfaat Teoritis

Penelitian ini memberikan informasi bahwa model Project Based Learning (PjBL) sebagai pembelajaran yang dapat mempengaruhi kemampuan berpikir kritis siswa pada pelajaran biologi.

2. Manfaat Praktis

a. $\underline{\text { Bagi Siswa }}$

i. Melatih kemampuan berpikir kritis siswa dalam pembelajaran biologi

ii. Melatih siswa untuk berkerja sama dalam kelompok untuk memecahkan masalah sehingga terbentuk rasa kebersamaan, saling menghargai, dan bertanggung jawab.

\section{b. Bagi Guru}

i. Memotivasi guru dalam melatihkan kemampuan berpikir siswa dalam pembelajaran biologi.

ii. Menambah alternatif solusi dalam melatihkan kemampuan berpikir kritis siswa dalam pembelajaran biologi.

iii. Menambah wawasan tentang model pembelajaran yang dapat melatih kemampuan berpikir kritis siswa. 


\section{c. $\underline{\text { Bagi Institusi }}$}

Memberikan saran perbaikan bagi

SMA Negeri 2 Karanganyar dalam mengembangkan kualitas pembelajaran biologi khususnya sebagai acuan model pembelajaran yang dapat melatihkan kemampuan berpikir kritis siswa sehingga mengahasilkan output yang berkualitas baik dan berdaya saing tinggi.

\section{Metode Penelitian}

Penelitian ini termasuk quasi eksperimen dengan pendekatan kuantitatif. Desain penelitian adalah posttest only non equivalent group design dengan menggunakan kelas eksperimen diberi perlakuan penerapan model Project Based Learning (PjBL) dan untuk kelas kontrol tidak diberikan perlakuan atau tetap menggunakan pendekatan konvensional (pendekatan yang biasa diterapkan di kelompok tersebut).

Populasi dalam penelitian ini adalah seluruh siswa kelas X SMA Negeri 2 Karanganyar. Teknik pengambilan sampel dengan cluster sampling, sehingga terpilih kelas $\mathrm{X} 1$ sebagai kelas eksperimen dan kelas X3 sebagai kelas kontrol.

Variabel bebas dalam penelitian ini adalah model Project Based Learning $(P j B L)$ diterapkan dikelas ekaperimen, dan pendekatan pembelajaran konvensional dengan metode ceramah, diskusi dan tanya jawab diterapkan dikelas kontrol. Variabel terikat dalam penelitian ini adalah kemampuan berpikir kritis siswa. Teknik pengumpulan data yang digunakan dalam penelitian ini adalah tes dan observasi. Metode tes digunakan untuk mengukur kemampuan berpikir kritis siswa. Tes yang dikembangkan dalam penelitian ini berupa soal uraian. Metode observasi digunakan untuk melihat keterlaksanaan sintaks model Project Based Learning $(P j B L)$ yang diterapkan di kelas yang diawasi oleh observer.

Tes uji coba pada instrumen penelitian dilakukan untuk mengetahui validitas dan reliabilitas. Uji validitas internal menggunakan validasi dari ahli. Uji validitas eksternal menggunakan produk moment. Uji reliabelitas menggunakan uji alfa.

Analisis data pada penelitian dengan menggunakan uji $t$. Sebelumnya dilakukan uji normalitas menggunakan uji Kolmogorov-Smirnov dengan koreksi lilifors dan uji homogenitas dengan uji Levene's.

\section{Hasil dan Pembahasan}

Data penelitian berupa nilai postes hasil kemampuan berpikir kritis. Data postes dianalisis dengan uji-t untuk mengetahui perbedaan hasil dari 
penerapan model Project Based Learning

$(P j B L)$ dan pendekatan konvensional (ceramah bervariasi).

\section{Uji Hipotesis}

Uji hipotesis yang digunakan adalah uji hipotesis komparatif dua sampel yang independen (tidak berkorelasi) dengan uji-t dibantu program aplikasi SPSS 16. Uji hipotesis ini adalah uji generalisasi rata-rata data dua sampel yang tidak berkorelasi (Sugiyono, 2012b:137). Tujuan dari uji t dua sampel adalah untuk membandingkan apakah kedua data sama atau berbeda (Riduwan, 2012:213). Sampel yang dikomparasikan adalah kemampuan berpikir kritis siswa pada kelas kontrol dengan model pembelajaran konvensional berupa ceramah bervariasi dan kelas eksperimen dengan model Project Based Learning (PjBL).

\section{Kemampuan Berpikir Kritis}

Hasil uji $\mathrm{t}$ untuk mengetahui pengaruh model Project Based Learning $(P j B L)$ terhadap keterampilan berpikir kritis dapat dilihat pada Tabel 1.3.

Tabel 1.3. Hasil analisis pengaruh model Project Based Learning (PjBL) terhadap kemampuan berpikir kritis.

\begin{tabular}{|c|c|c|c|c|c|}
\hline $\begin{array}{l}\text { Ranah } \\
\text { Kognitif }\end{array}$ & $\mathrm{t}$ & $\mathrm{df}$ & $\begin{array}{l}\text { Sig. } \\
(2- \\
\text { tailed) }\end{array}$ & kriteria & $\begin{array}{l}\text { Keputusan } \\
\text { uji }\end{array}$ \\
\hline $\begin{array}{l}\text { Nilai } \\
\text { kemampun } \\
\text { berpikir } \\
\text { kritis }\end{array}$ & -2.612 & 66 & 0,011 & Sig $<0,05$ & H0 ditolak \\
\hline
\end{tabular}

Berdasarkan keputusan uji pada Tabel 1.3 diketahui (sig) $>0,050$ dan nilai $t_{\text {hitung }}<\mathrm{t}_{(\alpha, d f)}$ sehingga $\mathrm{H}_{\mathrm{O}}$ ditolak dan H1 diterima, artinya ada perbedaan yang signifikan rata-rata kemampuan berpikir kritis berdasarkan model pembelajaran (kelompok kontrol dengan model pembelajaran konvensional dan kelompok eksperimen dengan model Project Based Learning (PjBL) sehingga diinterpretasikan bahwa penerapan model Project Based Learning (PjBL) berpengaruh terhadap kemampuan berpikir kritis siswa.

Penelitian ini menujukan bahwa model Project Based Learning (PjBL) berpengaruh terhadap kemampuan berpikir kritis siswa. Penelitian ini sejalan dengan penelitian yang dilakukan oleh Luthvitasari, dkk (2012) yang menyatakan model pembelajaran berbasis proyek berpengaruh terhadap kemampua berpikir kritis kelas XI TKJ (Teknik Komputer Jaringan) SMK Ma'arif Tanjungan Blora. Penelitian lain yang sejalan adalah Moerdiyanto (2011), berdasarkan penelitianya terhadap remaja putus sekolah di daerah Bantul, Yogyakarta yang bertujuan agar mereka memiliki kemampuan berpikir kritis dan mampu memecahkan perasalahan yang ada di lingkunganya sehingga mampu berwirausaha. Dan penelitian tersebut menunjukan bahwa Project Based 
Learning berpengaruh terhadap kemampuan berpikir kritis sehingga mampu memecahkan masalah dan mampu berwirausaha.

\section{Kesimpulan}

Berdasarkan hasil penelitian tentang pengaruh model Project Based Learning (PjBL) terhadap kemampuan berpikir kritis siswa dapat disimpulkan sebagai berikut:

Model pembelajaran model
Project Based Learning $(P j B L)$
berpengaruh nyata terhadap kemampuan berpikir kritis siswa kelas X SMA Negeri 2 Karanganyar semester II tahun pelajaran 2012/2013.

\section{Daftar Pustaka}

Amri, S. dan Ahmadi, K.I. (2010). Proses Pembelajaran Inovatif dan Kreatif dalam Kelas. Jakarta: Prestasi pustakarya

Apriono, D. (2009). Implementasi Metode Cllaborative Learning Dalam Meningkatkan Pemikiran Kritis Siswa. Prospektus, Tahun VII No. 2. Unirow. Tuban

Balitbang Kemendiknas. (2013). Di akses di http://litbang.kemdikbud.go.id/ sekretariat/hasilun/index.php/hasilun pada 28 Februari 2013.

Daroni. 2002. Pembelajaran Kooperatif Siswa di SLTP Melalui Model Jigsaw. Lembaran Ilmu Kependidikan Universitas Negeri Semarang. 31 (2), 225-241

Facione, P.A. (2013). Critical Thinking: What It Is and Why It Counts. California: Measured reason and the California academic press
Jacobsen, D., Eggen, P., dan Kauchak, D. (2009). Methods For Teaching : Metode- Metode Pengajaran Meningkatkan Belajar Siswa TKSMA EdisiBahasa Indonesia. Yogyakarta : Pustaka Pelajar

Luthviasari, N., Made, N.D.P., Linuwih, S. (2012). Implementasi Pembelajaran Fisika Berbasis Proyek Terhadap Ketrampilan Berpikir Kritis,Berpikir Kreatif Dan Kemahiran Generik Sains. Journal of Innovative Science Education. JISE 1 (2), 93-96

Mahanal, S., Darmawan, E., Corebima, A.D., dan Zubaidah, S. (2009). Pengaruh Pembelajaran Project Based Learning (PjBL) pada Materi Ekosistem terhadap Sikap dan Hasil Belajar Siswa SMAN 2 Malang. Skripsi. Universitas Negeri Malang. Malang.

Moerdiyanto dan Sunarta. (2012). Perluasan Implementasi Pendidikan Kewiraausahaan Model Project Based Learning Bagi Remaja Putus Sekolah Korban Gempa. Jural Economia, 8, No.1: 14-19

Riduwan. (2012). Dasar-Dasar Statistika. Bandung : Alfabeta

Schneider, D.K. (2005). Pembelajaran Berbasis Proyek. Diakses pada 9 januari 2013

Sugiyono. (2012). Metode Penelitian Pendidikan. Bandung : Alfabeta

Suryawati, E., Syafii, W., Afza, A. (2012). Pengembangan pembelajaran kontekstual rangka berbasis pendidikan karakter untuk meningkatkan sikap ilmiah dan ketrampilan berpikir kritis siswa sma dalam pembelajaran biologi. Skripsi. FKIP. Universitas riau

Susanti, E. dan Muchtar, Z. (2008). Pendekatan Project Based Learning Untuk Pembelajaran Kimia Koloid di SMA. Jurnal Pend.Mat \& Sains Vol 3(2), 106-122. ISSN:1907-7157. Sumatra Utara

The George Lucas Educational Foundation. (2005). How Does 
Project Based Learning Work?. Eutopia : University of Pheonix. Diambil pada tanggal 13 Januari 2013 dari http://www.edutopia.org/projectbased-learning-guide-implementation.
Usman, H dan Akbar. (2011). Pengantar Statistika. Jakarta : Bumi Akara Yamin, M. (2008). Paradigma Pendidikan Kontruktivistik. Jakarta: Gaung Persada Press. 